\title{
Protein and Water Distribution Across Visual Axis in Mouse Lens: A Confocal Raman MicroSpectroscopic Study for Cold Cataract
}

\author{
Yao $\mathrm{Li}^{1}$, Yuxing $\mathrm{Li}^{1}$, Xi $\mathrm{Liu}^{2}$, Yonghong $\mathrm{He}^{3}$ and Tian Guan ${ }^{3 *}$ \\ ${ }^{1}$ Tsinghua-Berkeley Shenzhen Institute (TBSI), Shenzhen, China, ${ }^{2}$ Department of Ophthalmology, Beijing Children's Hospital, \\ Capital Medical University, National Center for Children's Health, Beijing, China, ${ }^{3}$ Department of Life and Health, Tsinghua \\ Shenzhen International Graduate School, Shenzhen, China
}

Purpose: The aims of the study were to investigate cellular mechanisms of cold cataract in young lenses of wild-type C57BL/6J (B6WT) mice treated at different temperatures and to test a hypothesis that cold cataract formation is associated with the changes in lens protein and water distribution at different regions across lens fiber cells by Raman spectroscopy (RS).

OPEN ACCESS

Edited by:

Enza Fazio,

University of Messina, Italy

Reviewed by:

Romulo Ando,

University of São Paulo, Brazil

Valentina Venuti,

University of Messina, Italy

${ }^{*}$ Correspondence:

Tian Guan

guantian@sz.tsinghua.edu.cn

Specialty section:

This article was submitted to

Physical Chemistry and Chemical

Physics,

a section of the journal

Frontiers in Chemistry

Received: 01 September 2021

Accepted: 07 October 2021

Published: 15 November 2021

Citation:

LiY, LiY, LiuX, He Y and Guan T (2021) Protein and Water Distribution Across Visual Axis in Mouse Lens: A Confocal Raman MicroSpectroscopic Study for

Cold Cataract.

Front. Chem. 9:767696.

doi: $10.3389 /$ fchem.2021.767696
Methods: RS was utilized to scan the mouse lens at different regions with/without cold cataract. Three regions with various opacification along the equatorial axis in the anterior-posterior lens section were scanned. The intensity ratio of Raman bands at 2,935 and $3,390 \mathrm{~cm}^{-1}\left(I_{\mathrm{p}} / I_{\mathrm{w}}\right)$ were used to evaluate lens protein and water distribution. We further determined water molecular changes through Gaussian profiles of water Raman spectra.

Results: Three specific regions 1, 2, and 3, located at 790-809, 515-534, and 415-434 um away from the lens center, of postnatal day 14 B6WT lenses, were subjected to $\mathrm{RS}$ analysis. At $37^{\circ} \mathrm{C}$, all three regions were transparent. At $25^{\circ} \mathrm{C}$, only region 3 became opaque, while at $4^{\circ} \mathrm{C}$, both regions 2 and 3 showed opacity. The sum of the difference between $I_{p} / I_{w}$ and the value of linear fitting line from scattered-line at each scanning point was considered as fluctuation degree (FD) in each region. Among different temperatures, opaque regions showed relatively higher FD values (0.63 and 0.79 for regions 2 and 3 , respectively, at $4^{\circ} \mathrm{C}$, and 0.53 for region 3 at $25^{\circ} \mathrm{C}$ ), while transparent regions provided lower FD values (less than 0.27). In addition, the decrease in Gaussian peak II and the rising of Gaussian peak III and IV from water Raman spectra indicated the instability of water molecule structure in the regions with cold cataract.

Conclusion: Fluctuation degrees of RS data reveal new mechanistic information about cold cataract formation, which is associated with uneven distribution of lens proteins and water across lens fiber cells. It is possible that RS data partly reveals cold temperatureinduced redistribution of lens proteins such as intermediate filaments in inner fiber cells. This lens protein redistribution might be related to unstable structure of water molecules according to Gaussian profiles of water RS.

Keywords: cataract, cold cataract, lens, Raman spectroscopy, protein and water distribution 


\section{INTRODUCTION}

Cataract is the main cause of blindness among various eye diseases, which has always been a global health issue (Huang and Chen, 2018). Cold cataract is a phenomenon that opacification occurs in young mammalian lenses when cooled, and the whole process is reversible when warmed (Zigman and Lerman, 1964; Zigman and Lerman, 1965; Lo, 1989). By controlling the temperature, cold cataract is a convenient and realizable model for studying cataract and related physicochemical changes in the laboratory (Lo, 1989; Sivak et al., 1992). The formation and components of cold cataract have been studied via various methods in the past decades, including laser scanning (Sivak et al., 1992), NMR (Lerman et al., 1982; Lerman et al., 1983), and protein analyses (Broide et al., 1991; Song et al., 2009).

It has been proven that beaded filament is significant to the lens optical transparency (Blankenship et al., 2001; Song et al., 2009). In biochemistry level, $\alpha-, \beta-$, and $\gamma$-crystallin are related to the formation of cold cataract (Lo, 1989), and aggregation and phase separation of $\gamma$-crystallin play the most crucial role (Lerman et al., 1983; Broide et al., 1991). Therefore, $\gamma$-crystallin is considered to be the cryoprotein in cold cataract formation (Lerman et al., 1966; Siezen et al., 1985). Both intermediate filaments and crystallins are concerned with the formation of cold cataract. Furthermore, some other researches raised that supermolecular organization accounted for the formation of cold cataract rather than specific lens protein (Loewenstein and Bettelheim, 1979; Lerman et al., 1982). A further study on the mechanisms of cold cataract is still needed.

So far, there are various optical methods involved in interpreting cold cataract based on changes in optical signals. With the laser scanning system, the opacification of the lens can be evaluated for cold cataract by measuring the intensity of scattered light (Benedek et al., 1979; Petta et al., 2008), relative light transmittance (Banh and Sivak, 2004), as well as the equivalent focal length (Sivak et al., 1992). In addition, optical coherence tomography and optical coherence elastography were used to image the cold cataract model, providing structural information and biomechanical properties (Izatt et al., 1994; Zhang et al., 2018).

Raman spectroscopy (RS) is a non-invasive optical technique to determine the existence of certain molecules, which can be used in ophthalmology (Erckens et al., 2001; Lin et al., 2010). In eye lens study, Raman spectra from RS usually provide feature peaks, which are bound to vibrational modes of specific chemical bonds, such as $\mathrm{CH}_{2} / \mathrm{CH}_{3}$ vibration bond (Smeets et al., 1993) and disulfide bond (Ozaki et al., 1987). Furthermore, amino acid contents along the visual and equatorial axes were scanned in pig lens by Raman spectroscopy (Medina-Gutiérrez et al., 2004). For cold cataract study, Raman spectra for different species were acquired to test the changes in protein and water in lens with cold cataract (Ondruska and Hanson, 1983). Changes in the intensity ratio of tyrosine residues were found in the process of temperature alteration (Mizuno et al., 1984). To further analyze water and protein content in different regions of the lens based on acquired Raman spectra, different studies have used
RS to scan lens and lens slices at different positions (Bot et al., 1989; Huizinga et al., 1989). However, among previous researches on cold cataract with RS, the scanning region was usually wide instead of focusing on a small range across lens fiber cells.

The lack of organelles is a feature of lens fiber cells. Lenticular water may play an important role in lens opacification. The state of lens water among different species was studied with NMR (Rácz et al., 1979). Free and bound water mass was evaluated in different lens regions with age-dependent and advanced nuclear cataract (Heys et al., 2008), whereas, molecular level of water distribution was rarely analyzed in the formation of cold cataract. $\mathrm{RS}$ is qualified to reveal molecular information of solid and liquid $\mathrm{H}_{2} \mathrm{O}$ (Carey and Korenowski, 1998). Raman spectra of water can be analyzed through four of five fitted Gaussian profiles (Crupi et al., 2008; Huang et al., 2009; Baschenko and Marchenko, 2011). These Gaussian peaks are able to provide intra-molecular vibrational distributions of water, and are considered to be various structural types of hydrogen bond in $\mathrm{H}_{2} \mathrm{O}$ (Crupi et al., 2008; Huang et al., 2009).

In order to study the cellular mechanisms of cold cataract formation at molecular level, we used RS to scan young mice lens sections across fiber cells in vibratome section in vitro for the first time. In this work, we aimed to test the hypothesis that cold cataract formation is associated with the changes in lens protein and water distribution at different regions. With microscopic imaging, the opacity occurred as temperature decreased from $37^{\circ} \mathrm{C}$ to $4^{\circ} \mathrm{C}$. The opacity size varied under the treatment of different temperatures during the cold cataract formation. Raman spectra for three regions along the equatorial axis of anterior-posterior $(\mathrm{A} / \mathrm{P})$ lens section were obtained at different temperatures $\left(4^{\circ} \mathrm{C}, 25^{\circ} \mathrm{C}\right.$, and $\left.37^{\circ} \mathrm{C}\right)$. Protein and water content distribution was evaluated via related Raman vibrational band quantification. The distribution showed unevenness in opacification areas due to cold cataract. To further discover molecular changes in water, all the water spectra were analyzed in terms of Gaussian profiles.

\section{MATERIALS AND METHODS}

\section{Animals and Lens Image}

For cold cataract occurring in young mammalian lenses, female C57bl/6J wild-type mice (B6WT) at the age of postnatal day 14 were used as experiment subjects. All the disposals during experiments with mice were according to the approval of the Animal Ethics Committee of Tsinghua Shenzhen International Graduate School. Mice were euthanized with a suitable amount of $4 \%$ chloral hydrate and sacrificed by injecting an overdose of anesthetic after surgery. Lenses were immediately isolated under a dissecting microscope (Leica MZ 95) and were immersed into phosphate-buffered saline (PBS). Three lenses were treated at temperatures $4^{\circ} \mathrm{C}, 25^{\circ} \mathrm{C}$, and $37^{\circ} \mathrm{C}$, separately. To observe cold cataract, lenses were imaged with the microscope at different temperatures. Lenses developed full cold cataract from transparency in $4^{\circ} \mathrm{C}$ PBS solution in about $2 \mathrm{~min}$, and they were reversible to transparent in $37^{\circ} \mathrm{C}$ PBS solution in about $2 \mathrm{~min}$. Images of lens samples were captured according to the 


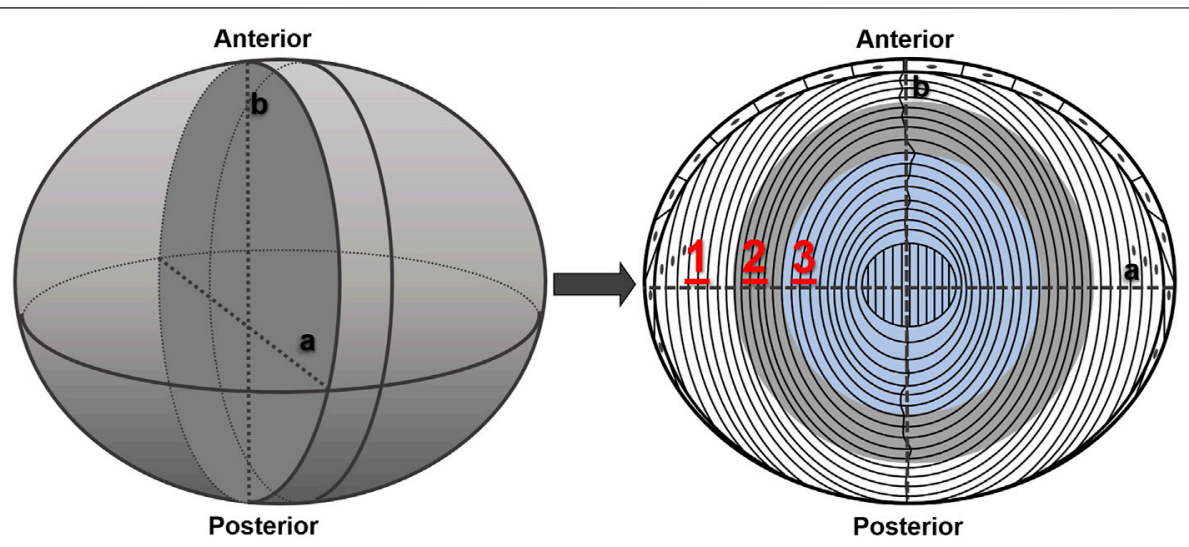

FIGURE 1 | Schematic graph of lens section with different scanning regions. The left plot demonstrates the whole lens after dissection, and the right plot depicts the anterior-posterior (A/P) section of the lens cut as scanning sample. Index lines (a and b) show the orientation of the slice. 1, 2, and 3 in red represents scanning regions 1 , 2 , and $3(20 \mu \mathrm{m}$ in length for each).

software on the computer related to the microscope. The size of lenses and cold cataract regions were recorded.

\section{Lens Vibratome Section}

According to previous studies, the fixation procedure shows no impact on water and protein content in the lenses (Bot et al., 1989; Huizinga et al., 1989; Siebinga et al., 1992). Before obtaining B6WT lens slices, fresh lenses should be fixed in $4 \%$ paraformaldehyde/PBS (PFA/PBS) solution at different temperatures. To examine $4^{\circ} \mathrm{C}$ cold cataract, fresh lenses were removed from eyeballs in $4^{\circ} \mathrm{C}$ PBS and fixed overnight in $4 \%$ PFA/ PBS solution at $4^{\circ} \mathrm{C}$. For lens samples treated at $25^{\circ} \mathrm{C}$ or $37^{\circ} \mathrm{C}$, fresh lenses were dissected in PBS at room temperature, and then transferred to $4 \% \mathrm{PFA} / \mathrm{PBS}$ solution at $25^{\circ} \mathrm{C}$ or $37^{\circ} \mathrm{C}$ for $3-5 \mathrm{~h}$. After fixation, lenses were washed with PBS three times and embedded in melting agarose gel on a plane block. The procedures of lens embedding and vibratome section are as follows: about $50 \mu \mathrm{l}$ of melted agarose gel drop was added on the surface of the plane block. A wedge was cut on the edge of the solid agarose gel to hold the lens with the cutting direction of anterior--posterior (A/P, along the optical axis) plane. Then to glue the lens and agarose gel on the block, about $0.5 \mu \mathrm{l}$ of superglue drop was added to the wedge via pipette without touching the lens. The lens and gel drop were covered with more agarose gel as a whole. After solidification, the block was superglued on the cutting plate of the vibratome microscope (Leica VT 1200S). Then sections with a thickness of $100 \mu \mathrm{m}$ were cut in a container of PBS. Lens sections around the equator were collected and kept in 4\% PFA/PBS solution again for post-fixation for $15 \mathrm{~min}$, then were washed with PBS three times. All the equatorial lens sections were scanned with Raman spectrometer at room temperature.

\section{Raman Spectroscopic Scanning Across Fiber Cells}

A confocal Raman microspectrometer (Horiba LabRAM HR800) was used for Raman spectra acquisition. Under the microscope of $\times 50$, the spectrum grating was 600 lines, and the hole was $100 \mu \mathrm{m}$. The excitation laser wavelength was $532 \mathrm{~nm}$ with the power of $25 \mathrm{~mW}$, and the spectral resolution was $1 \mathrm{~cm}^{-1}$. Through laser focus adjustment, the field of view was approximately $0.8 \mu \mathrm{m}$ in diameter.

Equatorial lens sections were placed on glass slides and covered with cover glasses of $0.14-\mathrm{mm}$ thickness. A drop of PBS solution was added between sliders and cover glasses to prevent lens sections from drying. To scan the lens section across the fiber cells, we set three scanning regions along the equatorial axis vertical to $\mathrm{A} / \mathrm{P}$ axis (Figure 1) based on the diameter of the lenses and cataract regions under different temperatures. The scanning direction was from cortex to nucleus. For each region, 20 points were collected with the step length of $1 \mu \mathrm{m}$, focusing on $50 \mu \mathrm{m}$ beneath the section surface to avoid uneven interference caused by cutting. In region 1 , the lens stays transparent under all temperatures. In region 2 , the lens turns opaque at $4^{\circ} \mathrm{C}$, while it becomes transparent at $25^{\circ} \mathrm{C}$. In region 3 , the lens forms cold cataract at both $4^{\circ} \mathrm{C}$ and $25^{\circ} \mathrm{C}$. Raman signal intensity as raw data were acquired for each wavenumber from 2,600 to $3,800 \mathrm{~cm}^{-1}$ at each scanning spot. The exposure time was $15 \mathrm{~s}$, with three averaged measurements.

\section{Statistical Analysis}

Statistical significance was evaluated with one-way analysis of variance (ANOVA) with Tukey's test, using the software Origin (OriginLab, United States). Values pf $p$ less than or equal to 0.05 , $0.01,0.001$, and 0.0001 were considered statistically significant.

\section{RESULTS}

\section{Lens Cold Cataract Formation in Microscopic Image}

After being immersed in PBS at different temperatures for more than $2 \mathrm{~min}$, lenses were imaged under the dissecting microscope. Three lenses were treated at each different temperature as one control group. As Figure 2A shows, from left to right, lenses were at $4^{\circ} \mathrm{C}, 25^{\circ} \mathrm{C}$, and $37^{\circ} \mathrm{C}$, separately. At $4^{\circ} \mathrm{C}$ and $25^{\circ} \mathrm{C}$, obvious opacity 

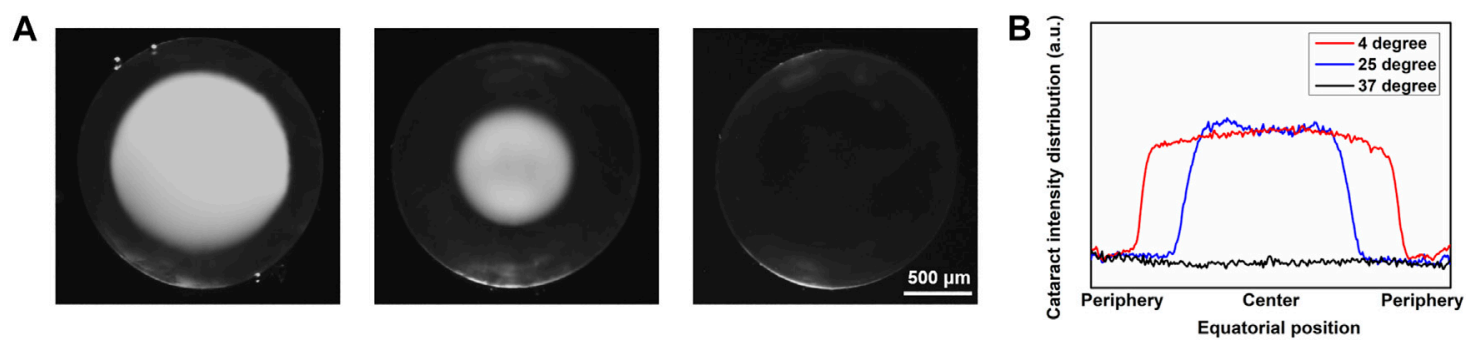

FIGURE 2 | Microscopic image of lens at different temperatures with cold cataract formation. (A) Anterior-view images of lens under dissecting microscope. From left to right, lenses were at $4^{\circ} \mathrm{C}, 25^{\circ} \mathrm{C}$, and $37^{\circ} \mathrm{C}$. Scale bar: $500 \mu \mathrm{m}$. (B) Plot profile of the equatorial line of the lenses at $4^{\circ} \mathrm{C}, 25^{\circ} \mathrm{C}$, and $37^{\circ} \mathrm{C}$.

due to cold cataract formation can be seen. However, the diameter of the opacity sphere at $4^{\circ} \mathrm{C}$ was much bigger than that at $25^{\circ} \mathrm{C}$. At $37^{\circ} \mathrm{C}$, no opacity was observed. When the temperature was raised from $4^{\circ} \mathrm{C} / 25^{\circ} \mathrm{C}$ to $37^{\circ} \mathrm{C}$, the opacity disappeared in about $2 \mathrm{~min}$, which supported that the cold cataract phenomenon was entirely reversible. There was no significant difference in the formation of cold cataract between the different sexes of mice. Also, there was no noticeable difference between the two lenses from a single mouse.

To quantitatively measure the light scattering distribution due to cold cataract, lens images captured by the dissecting microscope were further analyzed via software ImageJ. The plot profile of the gray value in the equatorial section of the lens is illustrated in Figure 2B. The light scattering distribution of the lens apparently differed from each other at $4^{\circ} \mathrm{C}, 25^{\circ} \mathrm{C}$, and $37^{\circ} \mathrm{C}$, respectively. The sizes of all lenses of the different mice were similar with a diameter of about $1,780 \pm 40 \mu \mathrm{m}$ (n 9). The diameters of the cold cataracts at $4^{\circ} \mathrm{C}$ were $1,319 \pm 28 \mu \mathrm{m}$, about $74 \%$ of the whole lens diameter. However, the diameter of the cold cataracts, at $25^{\circ} \mathrm{C}$ was $962 \pm 21.0 \mu \mathrm{m}$, about $54 \%$ of the whole lens diameter.

\section{Raman Spectra Acquisition and Processing} Based on the different sizes of cold cataract at $4^{\circ} \mathrm{C}, 25^{\circ} \mathrm{C}$, and $37^{\circ} \mathrm{C}$, regions 1, 2, and 3 were located at about 790-809, 515-534, and $415-434 \mu \mathrm{m}$ away from the lens center, respectively. To analyze protein distribution at each spot from three regions, three measurements were averaged during signal acquisition. Highwavenumber regions, $2,600-3,800 \mathrm{~cm}^{-1}$, were recorded as raw data in this work. Since the Raman intensities of 2,935 and $3,380 \mathrm{~cm}^{-1}$ bands represent $\mathrm{C}-\mathrm{H}$ vibration mode and $\mathrm{O}-\mathrm{H}$ vibration mode, lens protein and water content can be evaluated via these two bands, respectively.

Raman spectra were smoothed via Savitzky-Golay filter. Then background noises caused by fluorescence were subtracted through linear subtraction lines of the intensity of bands $2,600-2,800,2,800-3,030,3,030-3,100$, and $3,100-3,800 \mathrm{~cm}^{-1}$. The procedure of spectra processing is demonstrated in Figure 3A.

\section{Lens Protein and Water Quantitative Analyses}

To quantify protein content distribution in different regions under different temperatures, we evaluated the ratio of the intensity of $2,935 \mathrm{~cm}^{-1}$ band as protein content and the intensity of $3,380 \mathrm{~cm}^{-1}$ band as water content $\left(\mathrm{I}_{\mathrm{p}} / \mathrm{I}_{\mathrm{w}}\right)$ for each scanning point. Figure $3 \mathbf{B}$ depicts the average values $( \pm$ S.D.) of $\mathrm{I}_{\mathrm{p}} / \mathrm{I}_{\mathrm{w}}$ from all scanning points of the three lenses according to the three regions at $4^{\circ} \mathrm{C}, 25^{\circ} \mathrm{C}$, and $37^{\circ} \mathrm{C}$. For one lens, in regions 1,2 , and 3 , the average $I_{p} / I_{w}$ values were about $0.31,1.35$, and 1.81, respectively. This accorded with the rising of protein mass and the decreasing of water mass from lens cortex to nucleus. In regions 1 and $2, \mathrm{I}_{\mathrm{p}} / \mathrm{I}_{\mathrm{w}}$ values were not significantly different $(p>0.05)$, which revealed that protein total mass was nearly equal in these two regions with or without cold cataract. However, in region 3, $\mathrm{I}_{\mathrm{p}} / \mathrm{I}_{\mathrm{w}}$ values were significantly different $(p \leq 0.0001)$.

In order to visualize the scanning result from different regions, we demonstrated scatter line plots for $I_{p} / I_{w}$ values of every scanning point (scanning points 1-20) in three regions from every lens treated with each temperature in Figures 4A-C. For the $37^{\circ} \mathrm{C}$ group, scatter lines in all regions were relatively smooth. For the $25^{\circ} \mathrm{C}$ group, scatter lines in region 3 fluctuated more than those in regions 1 and 2 . For the $4^{\circ} \mathrm{C}$ group, scatter lines were relatively smooth only in region 1 , while scattered lines fluctuated obviously in regions 2 and 3. Generally, cold cataract impacted the protein content distribution in different regions under different temperatures.

To further quantify the fluctuation degree (FD), we processed linear fit to every scatter line. The absolute value of the difference between each scatter point and the linear-fit value line were summed up as FD value. As Figure 4D shows, in region 1, FD values were close with an average of 0.22 under different temperatures. However, in region 2, as Figure $4 \mathbf{E}$ shows, the FD value was much higher at $4^{\circ} \mathrm{C}(0.63 \pm 0.17)$ compared with $25^{\circ} \mathrm{C}(0.27 \pm 0.05)$ and $37^{\circ} \mathrm{C}(0.27 \pm 0.09)$. The $\mathrm{FD}$ values of the $25^{\circ} \mathrm{C}$ and $37^{\circ} \mathrm{C}$ groups were still close. In region 3 , as Figure $4 \mathrm{~F}$ shows, the FD values of the $4^{\circ} \mathrm{C}(0.79 \pm 0.20)$ and $25^{\circ} \mathrm{C}$ $(0.53 \pm 0.16)$ groups were relatively higher than the $37^{\circ} \mathrm{C}$ group. This revealed that the opacity from cold cataract formation altered protein content distribution among lens fiber cells. The lower the temperature, the more uneven the protein and water content distribution presented with the formation of cold cataract.

\section{Lens Water Molecular Level Analyses}

In order to acquire water molecular information from Raman spectra, the water spectra were analyzed through curve fitting 

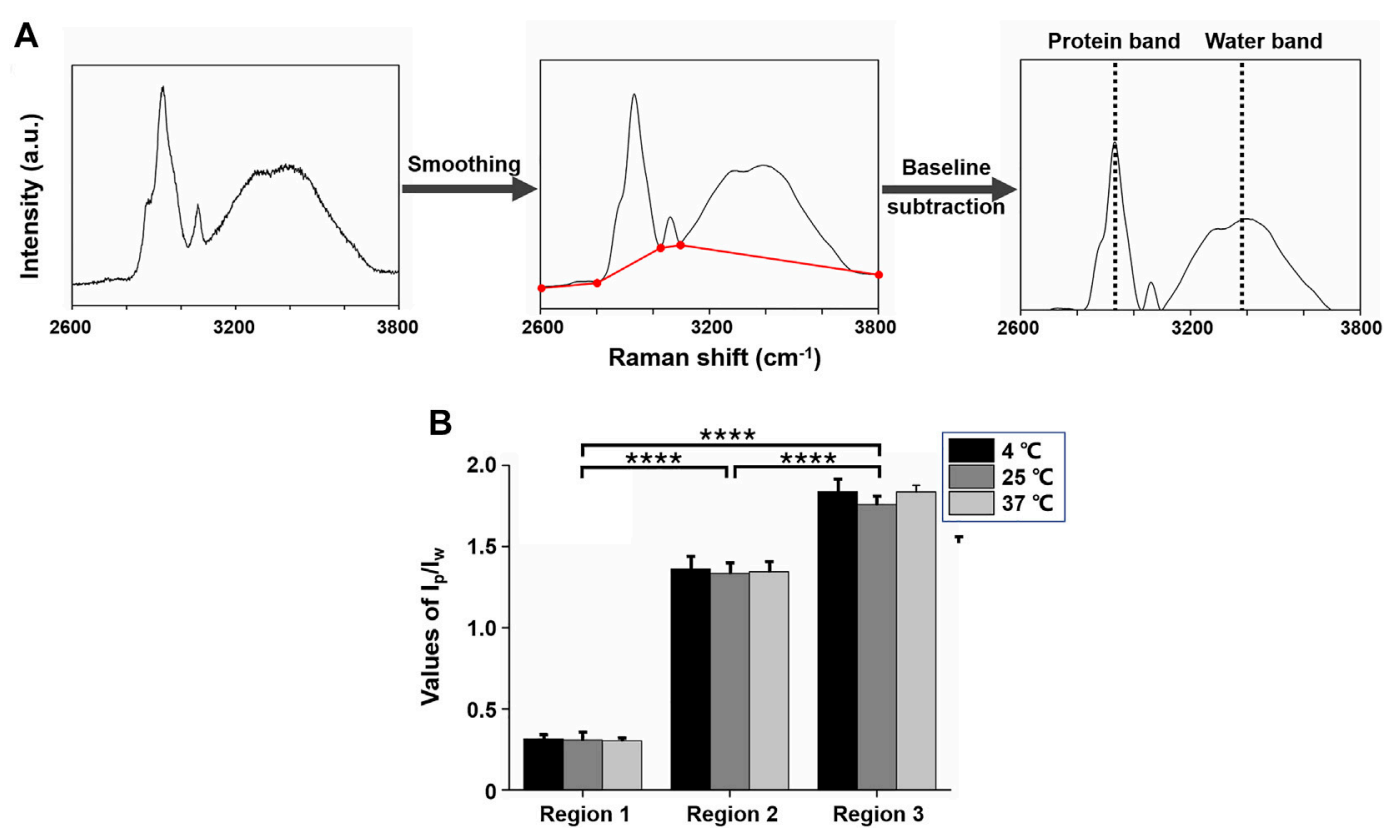

FIGURE 3 | High-wavenumber Raman spectra $\left(2,600-3,800 \mathrm{~cm}^{-1}\right)$ of mice lens. (A) Spectra processing procedure. (B): Average ratios of the intensity of protein and water brands $\left(I_{p} / I_{w}\right)$ for three regions from all three lenses treated with different temperatures. $I_{p} / I_{w}$ values increased from regions 1 to 3 and showed statistically significant differences between each region at $4^{\circ} \mathrm{C}, 25^{\circ} \mathrm{C}$, and $37^{\circ} \mathrm{C}\left({ }^{\star \star \star \star} p \leq 0.0001\right)$.

with the software Origin (OriginLab, United States). The strategy adopted for the curve fitting procedure was to use well-defined shape components of Gaussian functions, whose peaks were located at about (I) 3,230, (II) 3,400, (III) 3,530, and (IV) $3,650 \mathrm{~cm}^{-1}$. All three parameters for each Gaussian function were left to vary upon iteration. The statistical parameters were used as a guide to "best fit" The result of each fitted spectra was characterized by the adjusted R-square of $\sim 0.99$ to ensure the stability of the procedure. Typical Gaussian peaks (peak I to peak IV) are demonstrated in Figure 5A.

At $37^{\circ} \mathrm{C}$, the lenses were kept transparent in all regions. The average values of Gaussian peak amplitudes were evaluated according to all the scanning points (three lenses in total, $\mathrm{n}=$ $60)$. Figure $5 \mathbf{B}$ depicts the intensity change among the three regions under $37^{\circ} \mathrm{C}$. From regions 1 to 3 , the intensity of peaks I and II increased, while peaks III and IV decreased.

To reveal temperature dependence in water of normal lens, since there was no opacity in region 1 , whether at $4^{\circ} \mathrm{C}, 25^{\circ} \mathrm{C}$, or $37^{\circ} \mathrm{C}$, Gaussian peak intensities from this region were compared. As Figure $5 \mathrm{C}$ shows, from $37^{\circ} \mathrm{C}$ to $4^{\circ} \mathrm{C}$, the intensity of peaks I and II increased as temperature decreased, while peaks III and IV presented the opposite evolution with temperature.

Regions 2 and 3 from lenses treated with lower temperature, compared with region 1, presented various patterns of Gaussian components. In region 2 , when temperature decreased from $37^{\circ} \mathrm{C}$ to $25^{\circ} \mathrm{C}$, Gaussian peaks were still similar among different scanning points. Figures 6A,B show typical Gaussian wellfitted peaks of the lens water Raman spectra under $37^{\circ} \mathrm{C}$ and $25^{\circ} \mathrm{C}$. However, at $4^{\circ} \mathrm{C}$, Gaussian peaks were irregularly compared with $37^{\circ} \mathrm{C}$ and $25^{\circ} \mathrm{C}$. The intensity of peaks III and IV was higher, while peak II decreased at some points. The intensity of peak I was higher or lower at some points (Figure 6C).

In region 3, Gaussian peaks kept fixed relatively only at $37^{\circ} \mathrm{C}$, as Figure $6 \mathrm{D}$ shows. At $25^{\circ} \mathrm{C}$, peaks became fluctuated. The intensity of Peak II decreased, while peaks III and IV increased (Figure 6E). At $4^{\circ} \mathrm{C}$, the alteration in peaks was obvious and shared the same regulation with that in region 2 (Figure 6F).

\section{DISCUSSION}

Among previous researches, RS has been utilized to investigate changes in lens with cold cataract. Ondruska et al. studied the formation of dry and cold cataracts from duck, rat, and flounder lenses and found slight changes in Raman spectra (Ondruska and Hanson, 1983). Mizuno et al. investigated the tyrosine doublet in cold cataracts and discovered that some tyrosine residues possessed a change in their hydrogen bonding environment (Mizuno et al., 1984). Other studies basically evaluated protein and water mass in a large range to observe general changing trends (Bot et al., 1989; Huizinga et al., 1989). In this study, we illustrated the various opacity among three regions under different temperatures in $\mathrm{P} 14$ B6WT lenses. Region 1 stayed transparent under $4^{\circ} \mathrm{C}, 25^{\circ} \mathrm{C}$, and $37^{\circ} \mathrm{C}$, while region 2 became opaque only at $4^{\circ} \mathrm{C}$. Region 3 became opaque at both $4^{\circ} \mathrm{C}$ and $25^{\circ} \mathrm{C}$. These phenomena and the size of the various opacities with the formation of cold cataract correspond to previous studies from our group (Li et al., 2020). $\mathrm{I}_{\mathrm{p}} / \mathrm{I}_{\mathrm{w}}$ values represent the protein mass distribution of three regions. Whether at $4^{\circ} \mathrm{C}, 25^{\circ} \mathrm{C}$, or $37^{\circ} \mathrm{C}$, protein content increases from region 1 to region 3 . This result 
A Region 3
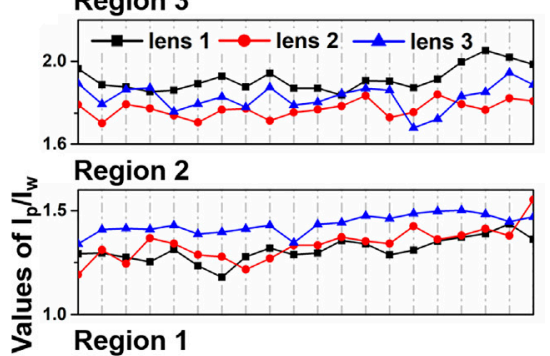

$0.5-$

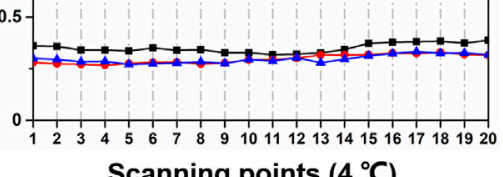

Scanning points $\left(4^{\circ} \mathrm{C}\right)$

D

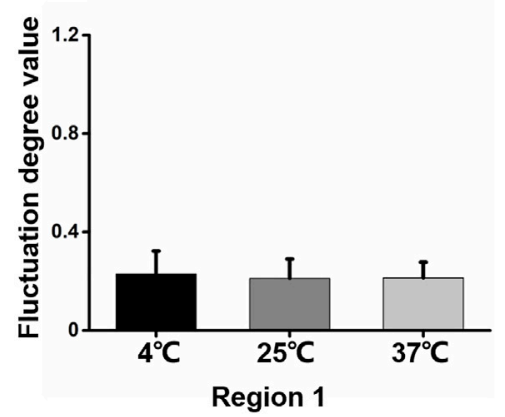

B
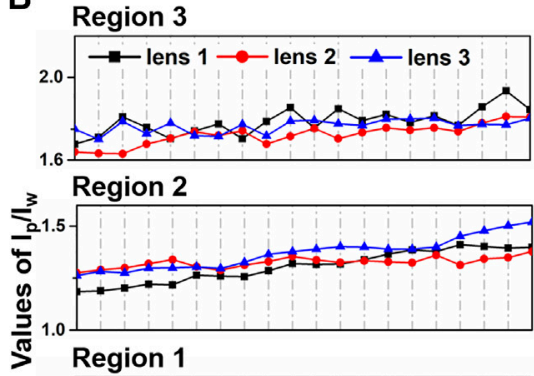

0.5 -

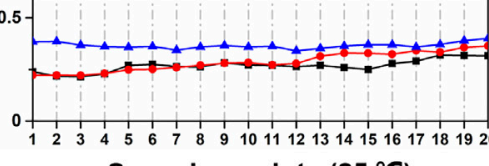

Scanning points $\left(25^{\circ} \mathrm{C}\right)$

E

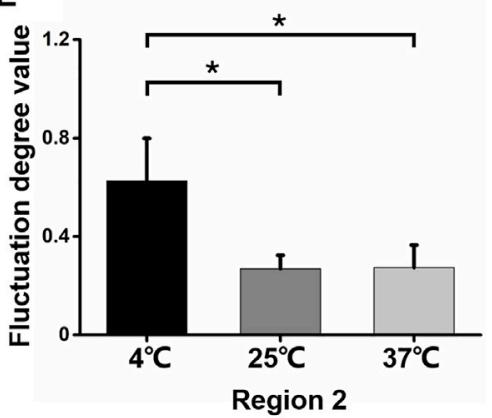

C
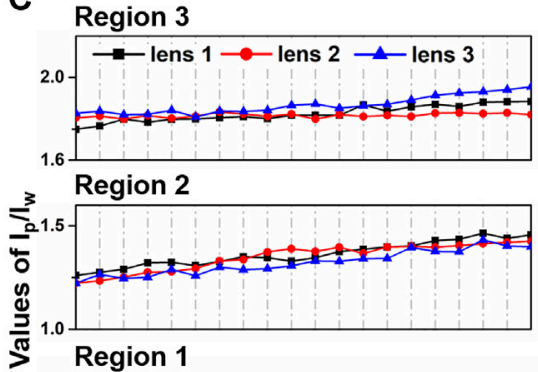

0.5

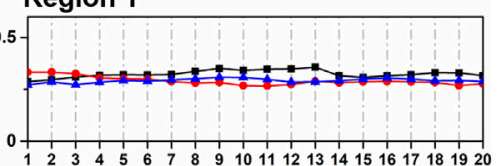

Scanning points $\left(37^{\circ} \mathrm{C}\right)$

$\mathbf{F}$

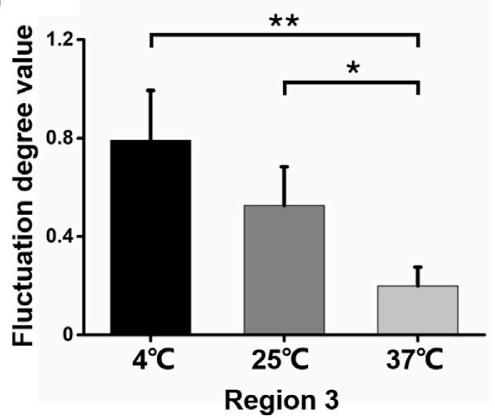

FIGURE 4 | The $\mathrm{I}_{\mathrm{p}} / \mathrm{I}_{\mathrm{w}}$ values for different regions and different temperatures. (A-C) Scattered-line plots of $\mathrm{I}_{\mathrm{p}} / \mathrm{I}_{\mathrm{w}}$ value for each scanning region at $4^{\circ} \mathrm{C}$, $25^{\circ} \mathrm{C}$, and $37^{\circ} \mathrm{C}$. In each small plot, the display regions of the values were set equal as 0.6. (D-F) The value of fluctuation degree for regions 1,2 and 3 at different temperatures, separately $\left({ }^{*} p \leq 0.05,{ }^{\star *} p \leq 0.01\right)$
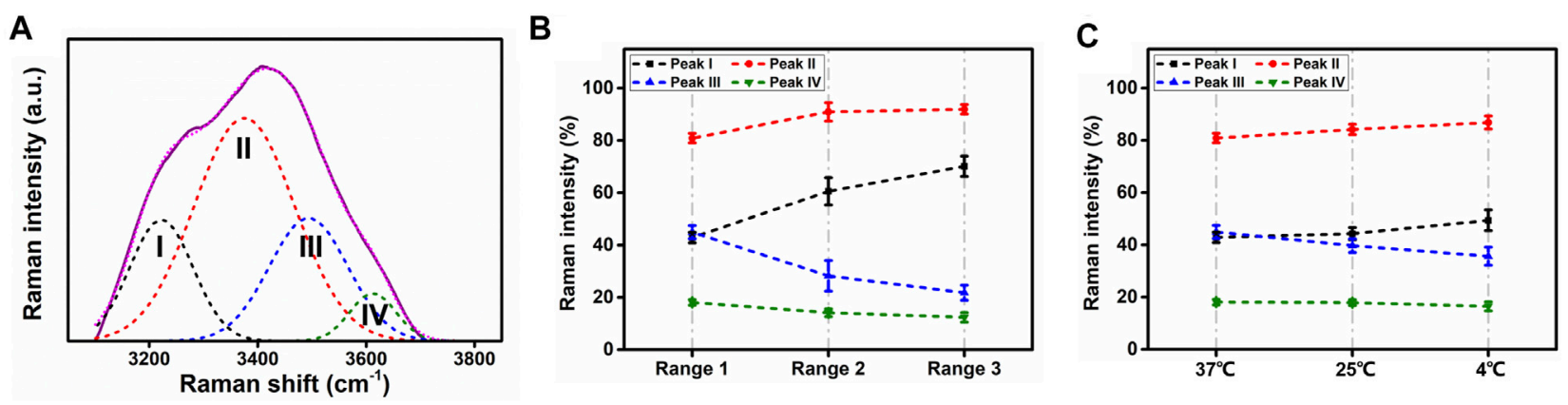

FIGURE 5 | Gaussian peaks and intensity changes without opacity. (A) Typical Gaussian fitting components as Gaussian peaks for Raman water spectra, ranging from 3,100 to 3,800 $\mathrm{cm}^{-1}$. I, II, III, and IV stand for Gaussian peaks I, II, III, and IV. (B) Raman intensity of four Gaussian peaks from three regions at $37^{\circ} \mathrm{C}$. (C) Raman intensity of four Gaussian peaks at $37^{\circ} \mathrm{C}, 25^{\circ} \mathrm{C}$, and $4^{\circ} \mathrm{C}$ in region 1.

supported that the relative protein to water content of lenses increases from cortex to nucleus (Bot et al., 1989; Huizinga et al., 1989).

Heys et al. analyzed free and total water in human normal and cataractous lenses with thermogravimetric analysis and differential scanning calorimetry (Heys et al., 2008). Through
RS, water spectra may not determine the water state in lens, but the structure information of water can be analyzed. In water spectra analyses with Gaussian profiles, peaks I and II represent fully four-hydrogen bonded water molecules, while peaks III and IV are associated to partly hydrogen-bonded free O-H (Crupi et al., 2008). In particular, peak I refers to the in-phase $\mathrm{O}-\mathrm{H}$ 


\section{A $\quad 37^{\circ} \mathrm{C}$ Region 2}

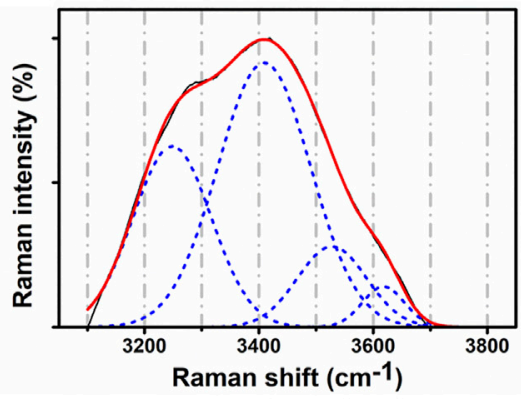

\section{C $\quad 4{ }^{\circ} \mathrm{C}$ Region 2}

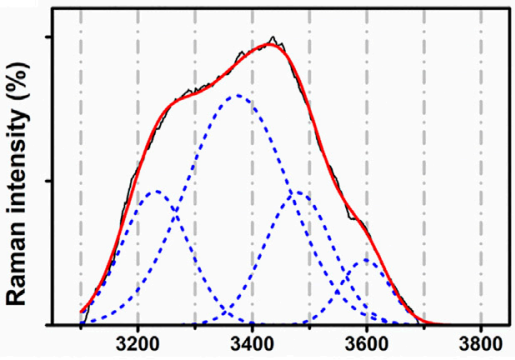

D $\quad 37^{\circ} \mathrm{C}$ Region 3

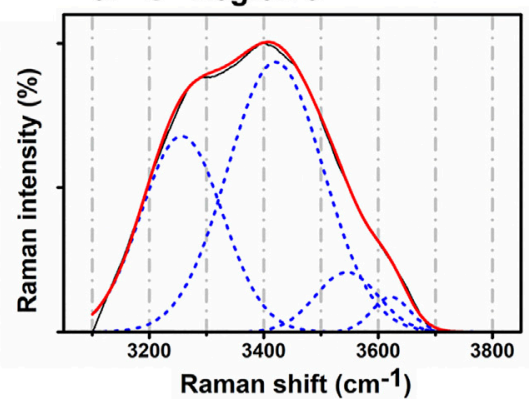

F $\quad 4{ }^{\circ} \mathrm{C}$ Region 3

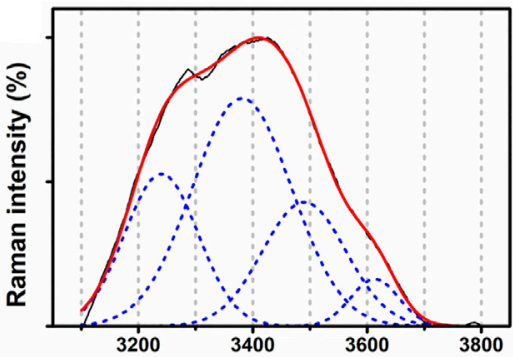

B $\quad 25^{\circ} \mathrm{C}$ Region 2

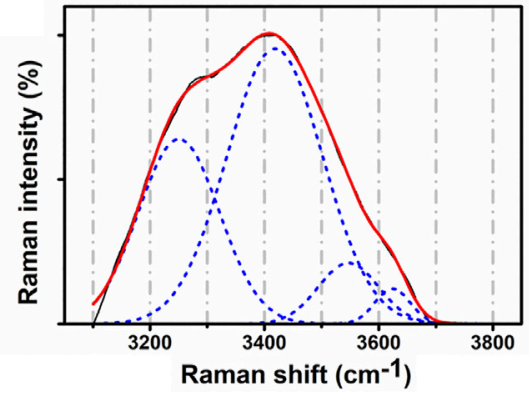

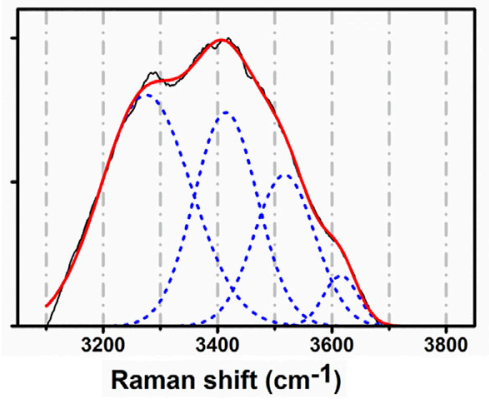

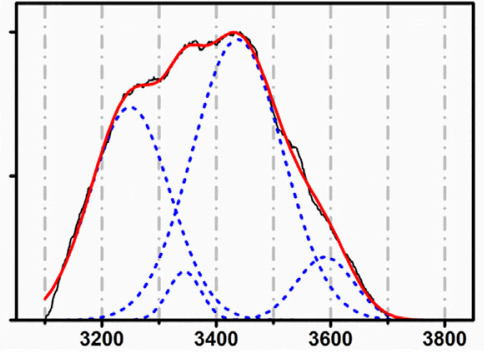

E $\quad 25^{\circ} \mathrm{C}$ Region 3

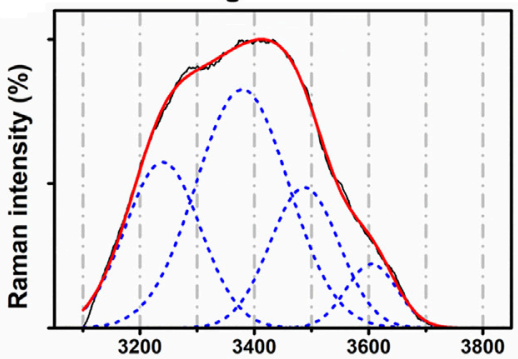

Raman shift $\left(\mathrm{cm}^{-1}\right)$
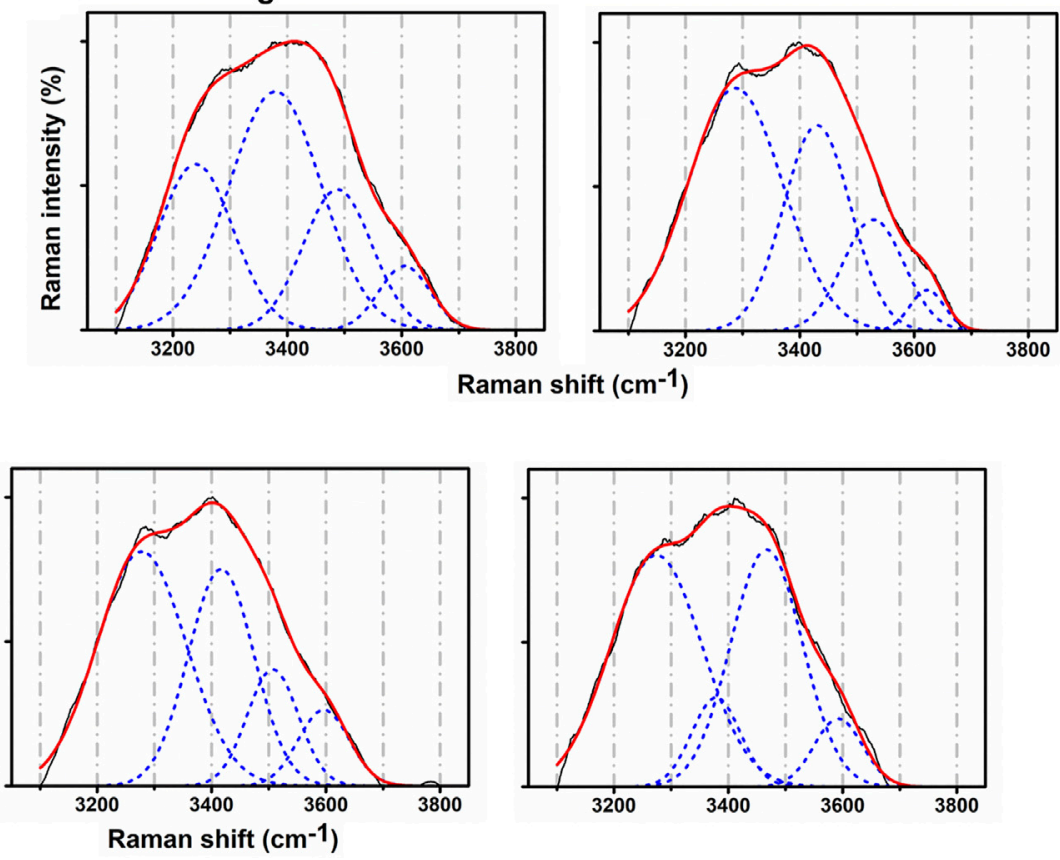

FIGURE 6 | Changes in Gaussian peaks from regions 2 and 3 at different temperatures. (A-C) Typical Gaussian peaks from region 2 at $37^{\circ} \mathrm{C}, 25^{\circ} \mathrm{C}$, and $4^{\circ} \mathrm{C}$. (D-F) Typical Gaussian peaks from region 3 at $37^{\circ} \mathrm{C}, 25^{\circ} \mathrm{C}$, and $4^{\circ} \mathrm{C}$.

stretching vibrations of hydrogen bonds from adjacent water molecules, while peak II is ascribed to out-of-phase $\mathrm{O}-\mathrm{H}$ stretching vibrations (Walrafen et al., 1986). In region 1 , as temperature decreased, although there was no cataract formation, the intensity of peaks I and II increased, while peaks III and IV decreased. This indicated that $\mathrm{O}-\mathrm{H}$ in water became more stable with more full hydrogen bonded water molecules, which supported the same change in bulk water and confined water (Crupi et al., 2008). However, when opacification occurred (in region 2 at $4^{\circ} \mathrm{C}$, in region 3 at $4^{\circ} \mathrm{C}$ and $25^{\circ} \mathrm{C}$ ), peaks III and IV increased, while peak II was constrained at some scanning points. The changing patterns of 
the peaks were irregularly compared with the regions without cataract. These results supported that hydrogen bonds break from water molecules, and out-of-phase $\mathrm{O}-\mathrm{H}$ stretching vibrations are weakened in lens fiber cells. This corresponded to the evidence that there was lower total water content in the center of advanced nuclear cataractous lenses, and the supported nuclear cataract formation may be associated with lower total hydration of the lens nucleus (Heys et al., 2008).

In this work, we used RS to scan the mice lens in the $20-\mu \mathrm{m}$ range micron by micron for the first time. By focusing on the protein and water bands of Raman spectra, we discovered that lens opacity due to cold cataract can lead to the fluctuation of protein and water distribution. Compared with regions without cold cataract, in region 3 , the $\mathrm{I}_{\mathrm{p}} / \mathrm{I}_{\mathrm{w}}$ scatter line variance revealed uneven accumulations of proteins at $4^{\circ} \mathrm{C}$ and $25^{\circ} \mathrm{C}$. In region 2 , only $4^{\circ} \mathrm{C}$ of treatment can cause obvious fluctuations in the scatter line. These results showed that low temperature may alter the accumulation or aggregation of filensin proteins in mice lenses, which supported our previous research and the concept of supermolecular organization of protein complexes causing the formation of cold cataract (Ondruska and Hanson, 1983; Li et al., 2020). Furthermore, we used Gaussian peaks of Raman water spectra to investigate cold cataract at the molecular level for the first time. The results supported that hydrogen bonds in water molecules may become unstable and are likely to participate in protein aggregation during cold cataract formation at low temperatures. Mouse cold cataract presents a practical model for understanding the changes in fiber cells during lens development at young ages. Future work is supposed to address the molecular mechanisms on how protein and water distribution become uneven and how water participates in cold cataract formation at low temperatures.

\section{CONCLUSION}

We scanned across the fiber cells of the lens along visual axis for the first time with RS. By scanning different regions $(20 \mu \mathrm{m}$ for each) with/without cold cataract at different temperatures, protein and water content distribution was quantified. At $4^{\circ} \mathrm{C}$, the protein and water distribution of both regions 2 and 3 were uneven. At $25^{\circ} \mathrm{C}$, however, only region 3 showed uneven protein and water distribution. At $37^{\circ} \mathrm{C}$, all regions were relatively even as comparison. The discovery testified that RS can be utilized to analyze changes in protein and water distribution across lens fiber

\section{REFERENCES}

Banh, A., and Sivak, J. G. (2004). Laser Scanning Analysis of Cold Cataract in Young and Old Bovine Lenses. Mol. Vis. 10, 144-147.

Baschenko, S., and Marchenko, L. (2011). On Raman Spectra of Water, its Structure and Dependence on Temperature. Semiconductor Physics. Quantum Electron. Optoelectronics 14 (1), 77-79. doi:10.15407/spqeo14.01.077 Benedek, G., Clark, J., Serrallach, E., Young, C., Mengel, L., Sauke, T., et al. (1979). Light Scattering and Reversible Cataracts in the Calf and Human Lens. Phil. Trans. R. Soc. Lond. A. 293 (1402), 329-340. doi:10.1098/ rsta. 1979.0100 cells. This proved that cold cataract formation is associated with the uneven protein and water distribution, revealing supermolecular mechanisms. Furthermore, Gaussian profiles of water Raman spectra demonstrated the activation of hydrogen-bonded free $\mathrm{O}-\mathrm{H}$ in water molecules. The lens protein and water redistribution might be related to the unstable structure of water molecules so that water may participate in this process during cold cataract formation.

\section{DATA AVAILABILITY STATEMENT}

The raw data supporting the conclusions of this article will be made available by the authors, without undue reservation.

\section{ETHICS STATEMENT}

The animal study was reviewed and approved by the Animal Ethics Committee of Tsinghua Shenzhen International Graduate School.

\section{AUTHOR CONTRIBUTIONS}

YL, YXL, and XL contributed to the conception and design of the study. YL conducted the experiments and performed the statistical analysis. YL wrote the first draft of the manuscript. $\mathrm{YH}$ and TG contributed to the manuscript revision. All authors read and approved the submitted version.

\section{FUNDING}

The work is supported by the Science and Technology Research Program of Shenzhen City (JCYJ20170412171856582, JCYJ20180508152528735) and Oversea Cooperation Foundation, Graduate School at Shenzhen, Tsinghua University (HW2018007).

\section{ACKNOWLEDGMENTS}

The authors thank Xiaohua Gong at the University of California, Berkeley, Berkeley, for the guidance of the research.

Blankenship, T. N., Hess, J. F., and FitzGerald, P. G. (2001). Development- and Differentiation-Dependent Reorganization of Intermediate Filaments in Fiber Cells. Invest. Ophthalmol. Vis. Sci. 42 (3), 735-742.

Bot, A. C. C., Huizinga, A., de Mul, F. F. M., Vrensen, G. F. J. M., and Greve, J. (1989). Raman Microspectroscopy of Fixed Rabbit and Human Lenses and Lens Slices: New Potentialities. Exp. Eye Res. 49 (2), 161-169. doi:10.1016/00144835(89)90086-9

Broide, M. L., Berland, C. R., Pande, J., Ogun, O. O., and Benedek, G. B. (1991). Binary-Liquid Phase Separation of Lens Protein Solutions. Proc. Natl. Acad. Sci. 88 (13), 5660-5664. doi:10.1073/pnas.88.13.5660

Carey, D. M., and Korenowski, G. M. (1998). Measurement of the Raman Spectrum of Liquid Water. J. Chem. Phys. 108 (7), 2669-2675. doi:10.1063/1.475659 
Crupi, V., Interdonato, S., Longo, F., Majolino, D., Migliardo, P., and Venuti, V. (2008). A New Insight on the Hydrogen Bonding Structures of Nanoconfined Water: A Raman Study. J. Raman Spectrosc. 39 (2), 244-249. doi:10.1002/ jrs. 1857

Erckens, R. J., Jongsma, F. H. M., Wicksted, J. P., Hendrikse, F., March, W. F., and Motamedi, M. (2001). Raman Spectroscopy in Ophthalmology: From Experimental Tool to Applications In Vivo. Lasers Med. Sci. 16 (4), 236-252. doi:10.1007/pl00011360

Heys, K. R., Friedrich, M. G., and Truscott, R. J. W. (2008). Free and Bound Water in normal and Cataractous Human Lenses. Invest. Ophthalmol. Vis. Sci. 49 (5), 1991-1997. doi:10.1167/iovs.07-1151

Huang, C.-C., and Chen, W. (2018). Raman Spectroscopic Analysis of Cataract Lens: A Compendious Review. Appl. Spectrosc. Rev. 53 (9), 689-702. doi:10.1080/05704928.2017.1416476

Huang, X. F., Wang, Q., Liu, X. X., Yang, S. H., Li, C. X., Sun, G., et al. (2009). Vibrational Dynamics of Water within Mesoporous Materials at Different Hydration Levels during Adsorption and Desorption Processes. J. Phys. Chem. C 113 (43), 18768-18771. doi:10.1021/jp9051566

Huizinga, A., Bot, A. C. C., de Mul, F. F. M., Vrensen, G. F. J. M., and Greve, J. (1989). Local Variation in Absolute Water Content of Human and Rabbit Eye Lenses Measured by Raman Microspectroscopy. Exp. Eye Res. 48 (4), 487-496. doi:10.1016/0014-4835(89)90032-8

Izatt, J. A., Hee, M. R., Swanson, E. A., Lin, C. P., Huang, D., Schuman, J. S., et al. (1994). Micrometer-Scale Resolution Imaging of the Anterior Eye In Vivo with Optical Coherence Tomography. Arch. Ophthalmol. 112 (12), 1584-1589. doi:10.1001/archopht.1994.01090240090031

Lerman, S., Ashley, D. L., Long, R. C., Goldstein, J. H., Megaw, J. M., and Gardner, K. (1982). Nuclear Magnetic Resonance Analyses of the Cold Cataract: Whole Lens Studies. Invest. Ophthalmol. Vis. Sci. 23 (2), 218-226.

Lerman, S., Megaw, J. M., Gardner, K., Ashley, D., Long, R. C., and Goldstein, J. H. (1983). NMR Analyses of the Cold Cataract. II. Studies on Protein Solutions. Invest. Ophthalmol. Vis. Sci. 24 (1), 99-105.

Lerman, S., Zigman, S., and Forbes, W. F. (1966). Properties of a Cryoprotein in the Ocular Lens. Biochem. biophysical Res. Commun. 22 (1), 57-61. doi:10.1016/ 0006-291x(66)90602-4

Li, Y., Liu, X., Xia, C. H., FitzGerald, P. G., Li, R., Wang, J., et al. (2020). CP49 and Filensin Intermediate Filaments Are Essential for Formation of Cold Cataract. Mol. Vis. 26, 603-612.

Lin, C-C., Kuo, M-T., and Chang, H-C. (2010). Raman Spectroscopy-A Novel Tool for Noninvasive Analysis of Ocular Surface Fluid. J. Med. Biol. Eng. 30 (6), 343-354. doi:10.5405/jmbe.846

Lo, W. K. (1989). Visualization of Crystallin Droplets Associated with Cold Cataract Formation in Young Intact Rat Lens. Proc. Natl. Acad. Sci. 86 (24), 9926-9930. doi:10.1073/pnas.86.24.9926

Loewenstein, M. A., and Bettelheim, F. A. (1979). Cold Cataract Formation in Fish Lenses. Exp. Eye Res. 28 (6), 651-663. doi:10.1016/0014-4835(79) 90066-6

Medina-Gutiérrez, C., Frausto-Reyes, C., Quintanar-Stephano, J. L., and SatoBerrú, R. (2004). Amino Acid Contents along the Visual and Equatorial Axes of a Pig Lens by Raman Spectroscopy. Spectrochimica Acta A: Mol. Biomol. Spectrosc. 60 (10), 2269-2274. doi:10.1016/j.saa.2003.11.025

Mizuno, A., Ozaki, Y., Itoh, K., Matsushima, S., and Iriyama, K. (1984). Raman Spectroscopic Evidence for the Microenvironmental Change of Some Tyrosine Residues of Lens Proteins in Cold Cataract. Biochem. biophysical Res. Commun. 119 (3), 989-994. doi:10.1016/0006-291x(84)90871-4

Ondruska, O., and Hanson, D. M. (1983). Raman Spectra of Duck, Rat, and Flounder Lenses and the Formation of Dry and Cold Cataracts. Exp. Eye Res. 37 (2), 139-143. doi:10.1016/0014-4835(83)90072-6
Ozaki, Y., Mizuno, A., Itoh, K., and Iriyama, K. (1987). Inter- and Intramolecular Disulfide Bond Formation and Related Structural Changes in the Lens Proteins. A Raman Spectroscopic Study In Vivo of Lens Aging. J. Biol. Chem. 262 (32), 15545-15551. doi:10.1016/s0021-9258(18)47760-5

Petta, V., Pharmakakis, N., Papatheodorou, G. N., and Yannopoulos, S. N. (2008). Dynamic Light Scattering Study on Phase Separation of a Protein-Water Mixture: Application on Cold Cataract Development in the Ocular Lens. Phys. Rev. E Stat. Nonlin Soft Matter Phys. 77 (6), 061904. doi:10.1103/ PhysRevE.77.061904

Rácz, P., Tompa, K., and Pocsik, I. (1979). The State of Water in normal Human, Bird and Fish Eye Lenses. Exp. Eye Res. 29 (6), 601-608. doi:10.1016/00144835(79)90015-0

Siebinga, I., Vrensen, G. F. J. M., Otto, K., Puppels, G. J., De Mul, F. F. M., and Greve, J. (1992). Ageing and Changes in Protein Conformation in the Human Lens: A Raman Microspectroscopic Study. Exp. Eye Res. 54 (5), 759-767. doi:10.1016/0014-4835(92)90031-m

Siezen, R. J., Fisch, M. R., Slingsby, C., and Benedek, G. B. (1985). Opacification of Gamma-Crystallin Solutions from Calf Lens in Relation to Cold Cataract Formation. Proc. Natl. Acad. Sci. 82 (6), 1701-1705. doi:10.1073/pnas.82.6.1701

Sivak, J. G., Stuart, D. D., and Weerheim, J. A. (1992). Optical Performance of the Bovine Lens Before and After Cold Cataract. Appl. Opt. 31 (19), 3616-3620. doi:10.1364/ao.31.003616

Smeets, M. H., Vrensen, G. F. J. M., Otto, K., Puppels, G. J., and Greve, J. (1993). Local Variations in Protein Structure in the Human Eye Lens: A Raman Microspectroscopic Study. Biochim. Biophys. Acta (Bba) - Protein Struct. Mol. Enzymol. 1164 (3), 236-242. doi:10.1016/0167-4838(93)90254-o

Song, S., Landsbury, A., Dahm, R., Liu, Y., Zhang, Q., and Quinlan, R. A. (2009). Functions of the Intermediate Filament Cytoskeleton in the Eye Lens. J. Clin. Invest. 119 (7), 1837-1848. doi:10.1172/jci38277

Walrafen, G. E., Fisher, M. R., Hokmabadi, M. S., and Yang, W. H. (1986). Temperature Dependence of the Low- and High-Frequency Raman Scattering from Liquid Water. J. Chem. Phys. 85 (12), 6970-6982. doi:10.1063/1.451384

Zhang, H., Wu, C., Singh, M., and Larin, K. V. (2018). "Quantifying Changes in Lens Biomechanical Properties Due to Cold Cataract with Optical Coherence Elastography," in Ophthalmic Technologies XXVIII, San Francisco, CA, February 19, 2018 (International Society for Optics and Photonics).

Zigman, S., and Lerman, S. (1964). A Cold Precipitable Protein in the Lens. Nature 203 (4945), 662-663. doi:10.1038/203662a0

Zigman, S., and Lerman, S. (1965). Properties of a Cold-Precipitable Protein Fraction in the Lens. Exp. Eye Res. 4 (1), 24-IN19. doi:10.1016/s0014-4835(65) 80005-7

Conflict of Interest: The authors declare that the research was conducted in the absence of any commercial or financial relationships that could be construed as a potential conflict of interest.

Publisher's Note: All claims expressed in this article are solely those of the authors and do not necessarily represent those of their affiliated organizations, or those of the publisher, the editors, and the reviewers. Any product that may be evaluated in this article, or claim that may be made by its manufacturer, is not guaranteed or endorsed by the publisher.

Copyright (C) $2021 \mathrm{Li}, \mathrm{Li}, \mathrm{Liu}, \mathrm{He}$ and Guan. This is an open-access article distributed under the terms of the Creative Commons Attribution License (CC BY). The use, distribution or reproduction in other forums is permitted, provided the original author(s) and the copyright owner(s) are credited and that the original publication in this journal is cited, in accordance with accepted academic practice. No use, distribution or reproduction is permitted which does not comply with these terms. 